We all know how the right person in a job

makes everything so easy while the wrong

person becomes a living nightmare.

\title{
The right person for the job
}

When I was working in general practice (more than 20 years ago) one of the questions I really dreaded hearing from a member of staff was 'Can I have a word with you please?' More often than not it heralded the resignation of that member of staff, something that always concerned me because it meant I had to go through the whole process of finding a replacement.

Imagine my surprise on moving into the commercial world to discover a completely different attitude to staff replacement. It was often seen as an opportunity (rather than a threat) because a new person in the job brought new ideas and a chance to reasssess the whole staff structure. This approach was so revolutionary that it took me a while to accept it, brought up as I had been by the rather more narrow attitudes of the small business. of course larger commercial companies can afford to be more relaxed because the greater numbers of staff involved means a single missing person is less critical. After all, one person leaving out of one hundred has much less effect than one out of six, but the more positive commercial attitude to the replacement of staff can have the same beneficial results in a small business or practice as well as a larger organisation.

It was more than just attitude, however, that surprised me when I left dental practice. The company I worked for insisted I had some training in recruitment and selection, and I was totally unprepared for the fact I would need two weeks learning about something I had spent my time in dental practice carrying out without any training at all. As a dental practitioner I had just 'muddled through' when faced with the situation. I spent no time in preparation, tried to cram too many interviews after surgery hours and spent most of the interview explaining the job rather than trying to find out about the individual. Looking back now I am both amazed and ashamed at the way that I treated all the hopefuls who responded to our rather basic advertisement in the local paper ('Dental Nurse wanted').

Thus to be trained for a whole week in recruitment and another whole week in selection was, as I hinted earlier, a revelation. Of course the reason it took so much time was because it involved practising the skills as well as learning what to do. But that training has stood me in good stead since, because the same principles of recruitment and selection apply whether you are looking for a dental nurse, a secretary, an assistant editor for the $B D J$, a dental associate or the director of a corporate body.

Yet, despite the obvious importance of good recruitment and selection, most dentists receive little or no skills training in this at all. Information and help in the mechanics is available from the BDA, both in the form of the Advice Sheet (D12) and the practical advice provided in the BDA Compendium. Outside dentistry books are obviously available on the subject, and some training in recruitment and selection for vocational trainers is also provided to help them select a VDP. But how to design an effective advertisement, how to draw up a shortlist of applicants based on interpreting CVs or applications forms, and most importantly how to interview properly are only scantly covered in courses and training available. When it does occur, as far as I know, it is nothing like the skills training I received in my two weeks training for the company I worked for.

Does this matter? I believe it does, because choosing the right people to work in the dental practice or dental organisation is absolutely critical. We all know how the right person in a job makes everything so easy while the wrong person becomes a living nightmare. After all, the behaviour of the whole dental team affects total patient care, possibly more from the patients' viewpoint than many other aspects of dentistry where training is plentiful. Perhaps even more relevant for the general practitioner considering an associate or a partner, choosing the right person can have significant and far-reaching effects for many years.

The only problem is, good recruitment and selection training does not help when you choose the wrong person. But dealing with that is another story. 